\title{
Calagem e desenvolvimento radicular, nutrição e produção de laranja 'Valência' sobre porta-enxertos e sistemas de preparo do solo
}

\author{
Pedro Antonio Martins Auler(1), Carmen Silvia Vieira Janeiro Neves( ${ }^{(2)}$, Jonez Fidalski(1) \\ e Marcos Antonio Pavan(3) \\ (1)Instituto Agronômico do Paraná (IAPAR), Caixa Postal 564, CEP 87701-970 Paranavaí, PR. E-mail: aulerpe@iapar.br, fidalski@iapar.br
(2)Universidade Estadual de Londrina, Centro de Ciências Agrárias, Caixa Postal 6.001, CEP 86051-980 Londrina, PR.
E-mail: csvjneves@uel.br (3)IAPAR, Caixa Postal 481, CEP 86001-970 Londrina, PR. E-mail: mpavan@iapar.br
}

\begin{abstract}
Resumo - O objetivo deste trabalho foi avaliar o efeito da calagem e de porta-enxertos sobre a quantidade de raízes, a nutrição e a produção de laranjeira 'Valência', em diferentes sistemas de preparo do solo. O experimento foi instalado em blocos ao acaso, com parcelas subsubdivididas e três repetições. As parcelas consistiram de dois sistemas de preparo do solo: convencional e com preparo mínimo. As subparcelas consistiram de níveis de calagem: com ou sem. As subsubparcelas consitiram de três porta-enxertos: limoeiro 'Cravo' (Citrus limonia), tangerineira 'Cleópatra' (Citrus reshni) e Poncirus trifoliata. O tratamento com calagem recebeu $3 \mathrm{Mg} \mathrm{ha}^{-1} \mathrm{de}^{2}$ calcário dolomítico, antes da implantação, e 1,65 $\mathrm{Mg}$ ha $^{-1}$ quatro anos após o plantio. A produção foi avaliada durante 12 anos; o teor de $\mathrm{Ca}$ e $\mathrm{Mg}$ nas folhas foram avaliados 13 anos após a implantação do experimento; e as raízes e as características químicas do solo, 14 anos após a implantação. O preparo de solo, e sua interação com os demais fatores, não influenciou as variáveis avaliadas. O limoeiro 'Cravo' adaptou-se melhor à acidez, ao $\mathrm{Al}$ e a menores teores de $\mathrm{Ca}$ e $\mathrm{Mg}$ no solo, e não respondeu ao tratamento com calagem. Poncirus trifoliata apresentou a pior adaptação à acidez do solo, com aumentos de $126 \%$ na quantidade de raízes e de $26,4 \%$ na produção de frutos em razão da calagem.
\end{abstract}

Termos para indexação: Citrus sinensis, Poncirus trifoliata, cálcio, tolerância ao Al.

\section{Liming and root development, nutrition and production of 'Valência' orange on rootstocks and soil tillage systems}

\begin{abstract}
The objective of this work was to evaluate the effect of liming and of rootstocks on root amount, and on the nutrition and yield of 'Valência' orange, in different soil tillage systems. The experiment was set up in a randomized block design with split-split-plot arrangement and three replicates. The plots consisted of two soil tillage systems: conventional tillage or minimum tillage. The sub-plots consisted of two liming levels: with or without liming. The sub-sub-plots consisted of three rootstocks: 'Rangpur' lime (Citrus limonia), 'Cleopatra' mandarin (Citrus reshni) and Poncirus trifoliata. The liming-treatment received $3 \mathrm{Mg} \mathrm{ha}^{-1}$ of dolomite limestone before the implantation, and $1.65 \mathrm{Mg} \mathrm{ha}^{-1}$ four years after planting. Fruit production was evaluated during 12 years; $\mathrm{Ca}$ and $\mathrm{Mg}$ leaf contents were evaluated 13 years after the experiment implantation; and roots and soil chemical attributes, 14 years after the implantation. Soil tillage systems and their interaction with the other factors did not influence the evaluated variables. 'Rangpur' lime showed the highest adaptation to soil acidity, $\mathrm{Al}$ and to the lower contents of $\mathrm{Ca}$ and $\mathrm{Mg}$, with no response to liming. Poncirus trifoliate showed the lowest adaptation to soil acidity, and lime increased its root amount in $126 \%$ and its fruit production in $26.4 \%$.
\end{abstract}

Index terms: Citrus sinensis, Poncirus trifoliata, calcium, Al tolerance.

\section{Introdução}

A laranjeira 'Valência' está entre as cultivares mais plantadas no Brasil e no mundo. Os porta-enxertos limoeiro 'Cravo' e tangerineira 'Cleópatra' são os mais utilizados nas principais regiões citrícolas do Brasil, e P. trifoliata, em determinadas condições, tem grande potencial de utilização por induzir menor porte às copas, boa eficiência de produção, além de melhor qualidade aos frutos (Stenzel et al., 2005; Auler, 2010).
As plantas cítricas são consideradas sensíveis à acidez do solo e a elevados teores de Al trocável (Anderson, 1987; Nogueira et al., 1989; Quaggio et al., 1992). Os citros caracterizam-se também por sua grande demanda por $\mathrm{Ca}$, cuja concentração nas folhas e em outros tecidos da planta, com exceção dos frutos, é superior à dos demais nutrientes minerais (Mattos Júnior et al., 2005). Baixos teores de $\mathrm{Ca}$ no solo limitam o desenvolvimento radicular dos citros (Pavan \& Jacomino, 1998; Sobral et al., 2009), com reflexos

Pesq. agropec. bras., Brasília, v.46, n.3, p.254-261, mar. 2011 
negativos sobre a produção de frutos (Anderson, 1987). $\mathrm{O} \mathrm{Mg}$, embora exigido em quantidades bem inferiores ao $\mathrm{Ca}$, pode limitar a produção de frutos quando seu suprimento pelo solo é baixo (Quaggio et al., 1992).

No Brasil, os resultados do uso de calagem em citros para a produção de frutos têm variado entre ausência de resposta ou resposta com incrementos de baixa magnitude (Boaretto et al., 1996). No entanto, é reduzido o número de trabalhos de longa duração, que tenham avaliado os efeitos da calagem sobre a produção, e abordado o uso de porta-enxertos diferentes do limoeiro 'Cravo'. Essa constatação é importante, já que são conhecidas diferenças entre porta-enxertos quanto à resposta à calagem, no desenvolvimento de raízes (Pavan \& Jacomino, 1998), e quanto à tolerância ao Al trocável (Santos et al., 1999; Pereira et al., 2003). Além disso, para $P$. trifoliata, sob copa de laranjeira 'Valência', por exemplo, não foram encontrados relatos de resposta à calagem (Auler, 2010).

Este trabalho teve como objetivo avaliar o efeito da calagem e de porta-enxertos sobre a quantidade de raízes, a nutrição e a produção da laranjeira 'Valência', em diferentes preparos do solo.

\section{Material e Métodos}

$\mathrm{O}$ experimento foi instalado em área situada a $23^{\circ} 09^{\prime} 12^{\prime \prime} \mathrm{S}$ e $52^{\circ} 08^{\prime} 40^{\prime \prime} \mathrm{W}$, a $434 \mathrm{~m}$ de altitude, no Município de Nova Esperança, em Latossolo Vermelho distrófico de textura arenosa média, originado do arenito da Formação Caiuá, na região noroeste do Paraná. O clima da região é subtropical Cfa, segundo Köppen, caracterizado pela concentração das chuvas no verão, sem estação seca definida, e precipitação anual de $1.400 \mathrm{~mm}$.

Utilizou-se o delineamento experimental de blocos ao acaso, com arranjo em parcelas subsubdivididas, com três repetições e três plantas úteis por parcela, no total de 36 subsubparcelas experimentais. Nas parcelas, foram estudados dois tipos de preparo do solo: o convencional e uma forma de preparo mínimo em faixa (Auler, 2010), preconizado para implantação de pomares de citros (Auler et al., 2008). A calagem foi avaliada nas subparcelas, com dois tratamentos: com e sem adição de calcário. Nas subsubparcelas, avaliaramse os porta-enxertos: limoeiro 'Cravo' (Citrus limonia Osb.), tangerineira 'Cleópatra' (C. reshni hort. ex Tan.) e Poncirus trifoliata (L.) Raf. A cultivar da copa foi a Valência 718 [C. sinensis (L.) Osb.], acesso IAPAR-94.
O experimento foi implantado em janeiro de 1994, no espaçamento de $7 \times 4 \mathrm{~m}$, com 357 plantas ha ${ }^{-1}$. Em amostragem realizada em setembro de 1993, o solo apresentava os seguintes atributos químicos na camada de $0-20 \mathrm{~cm}$ de profundidade: $1,5 \mathrm{mg} \mathrm{dm}^{-3} \mathrm{de}$ $\mathrm{P} ; 8,9 \mathrm{~g} \mathrm{dm}^{-3}$ de $\mathrm{C}$; $\mathrm{pH}_{\mathrm{CaCl} 2}$ de 4,5; teores trocáveis de $\mathrm{H}+\mathrm{Al}, \mathrm{Al}, \mathrm{Ca}, \mathrm{Mg}, \mathrm{K}$ e CTC de 4,28, 0,24, 1,18, 0,74, 0,37 e $6,57 \mathrm{cmol}_{\mathrm{c}} \mathrm{dm}^{-3}$, respectivamente; saturação por bases de $34,8 \%$ e por Al de $9,5 \%$. Na camada de 20 $40 \mathrm{~cm}$, os resultados foram os seguintes: $1,1 \mathrm{mg} \mathrm{dm}^{-3}$ de $\mathrm{P} ; 6,9 \mathrm{~g} \mathrm{dm}^{-3} \mathrm{de} \mathrm{C} ; \mathrm{pH}_{\mathrm{CaCl} 2}$ de 4,2; teores trocáveis de $\mathrm{H}+\mathrm{Al}, \mathrm{Al}, \mathrm{Ca}, \mathrm{Mg}, \mathrm{K}$ e CTC de 4,61, 0,65, 0,95, 0,37, 0,12 e $6,05 \mathrm{cmol}_{\mathrm{c}} \mathrm{dm}^{-3}$, respectivamente; saturação por bases de $23,8 \%$ e por Al de $31,1 \%$. O carbono orgânico (C) foi determinado pela metodologia de Walkley e Black, $\mathrm{K}$ e $\mathrm{P}$ foram extraídos em solução de Mehlich 1

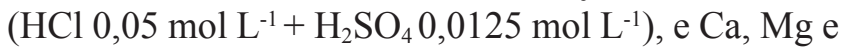
Al foram extraídos com solução de $\mathrm{KCl} 1 \mathrm{~mol} \mathrm{~L}^{-1}$.

Em outubro de 1993, $3 \mathrm{Mg} \mathrm{ha}^{-1}$ de calcário foram distribuídos em área total, na superfície do solo, e incorporados à profundidade de $20 \mathrm{~cm}$, nas subparcelas do tratamento com calagem. Em agosto de 1998, foi reaplicado, nos tratamentos com calagem, mais 1,65 Mg ha ${ }^{-1}$ de calcário em superfície, sem incorporação. Em ambas as aplicações, foi utilizado calcário dolomítico com PRNT de $75,1 \%$ e teores de $\mathrm{CaO}$ e $\mathrm{MgO}$ de 29 e $19 \%$, respectivamente. A quantidade de calcário foi calculada para elevar a saturação por bases a $70 \%$.

Cada cova de plantio recebeu $500 \mathrm{~g}$ de superfosfato simples, e foram aplicados, em cobertura, $150 \mathrm{~kg} \mathrm{ha}^{-1} \mathrm{de}$ $\mathrm{N}, 60 \mathrm{~kg} \mathrm{ha}^{-1}$ de $\mathrm{P}_{2} \mathrm{O}_{5}, 100 \mathrm{~kg} \mathrm{ha}^{-1}$ de $\mathrm{K}_{2} \mathrm{O}$ e $0,5 \mathrm{~kg} \mathrm{ha}^{-1}$ de $\mathrm{B}$, por ano. Foram realizadas adubações foliares $(0,2 \%$ do produto comercial) anuais com $\mathrm{Zn}$ e, com menor frequência, de $\mathrm{B}$, Mn e Ca, além de duas adubações orgânicas de 2 e $3 \mathrm{~kg}$ por planta, aplicadas em agosto de 2004 e de 2005, respectivamente. As entrelinhas das laranjeiras foram mantidas com cobertura vegetal espontânea, com predomínio de Urochloa decumbens e de grama mato-grosso (Paspalum notatum). O manejo dessa vegetação foi realizado com roçadeira, duas vezes ao ano, e com capinas manuais ou herbicida, nas linhas de plantio, três vezes por ano, tendo-se mantido a massa vegetal roçada sobre o solo.

As avaliações da produção foram realizadas de 1996 a 2008, em três plantas úteis por parcela, tendo-se obtido a massa total de frutos por planta no momento em que atingiam a maturação adequada para o consumo 
- normalmente em outubro. As produções acumuladas, no período total (1996 a 2008) e nos últimos três anos avaliados (2006 a 2008), foram determinadas. O período das três últimas safras (2006 a 2008) foi incluído principalmente pelo seu maior distanciamento da última calagem realizada.

A amostragem para análise dos teores foliares totais de nutrientes foi realizada em fevereiro de 2007, nas $3^{\mathrm{a}}$ e $4^{\mathrm{a}}$ folhas a partir do fruto, em cada quadrante das plantas úteis, na altura mediana da copa. As folhas foram secas e moídas, e as análises químicas foliares foram efetuadas conforme Miyazawa et al. (1992), com a solução de $\mathrm{HCl} 1 \mathrm{~mol} \mathrm{~L}^{-1}$ para extração do $\mathrm{Ca}$ e $\mathrm{Mg}$.

As raízes foram coletadas em abril de 2008, na área correspondente ao limite da projeção da copa da planta útil central de cada subsubparcela, em quatro profundidades $(0-10,10-20,20-40$ e $40-60 \mathrm{~cm})$, com trado de aço inox, com copo coletor com $7,3 \mathrm{~cm}$ de diâmetro interno e extremidade cerrilhada. Em cada subsubparcela, foram coletadas duas repetições em lados opostos da planta, distantes, em média, 1,8 m da linha de plantio no 'Cravo', 1,9 m na 'Cleópatra' e 1,6 m em $P$. trifoliata, de acordo com a projeção da copa. As raízes foram separadas do solo por meio de lavagem em água corrente, em peneiras com malha de 0,5 e $1 \mathrm{~mm}$, e foram secadas em estufa por 60 horas a $55^{\circ} \mathrm{C}$. Com auxílio de lupa de mesa com aumento de 10 vezes, as raízes de citros foram separadas de outras raízes e de impurezas, e apenas aquelas com até $1 \mathrm{~mm}$ de espessura foram utilizadas para obtenção da massa de matéria seca de raízes (MSR) e avaliação do efeito dos tratamentos (Souza et al., 2007). A densidade de raízes foi obtida com a divisão da MSR pelo volume de solo amostrado. Antes de se fazer a lavagem para a separação das raízes, foi retirada uma amostra de solo de cada uma das duas repetições, para compor uma única amostra composta de cada subsubparcela, destinada às análises para determinação dos atributos químicos do solo.

Os dados de produção de frutos, soma da MSR das duas repetições, para cada profundidade do solo, e das análises químicas do solo e das folhas foram submetidos à análise de variância de acordo com o delineamento em parcelas subsubdivididas. A comparação de médias foi realizada pelo teste de Tukey, a 5\% de probabilidade $(n=36)$. Análises de correlações lineares simples (Pearson) foram realizadas para cada porta-enxerto $(\mathrm{n}=12)$, entre a variável MSR e os atributos químicos do solo. A significância do coeficiente de correlação (r) foi testada pelo teste t, e a natureza da correlação entre essas variáveis foi analisada por meio de diagramas de dispersão, e as curvas de regressão foram ajustadas aos pontos de distribuição.

\section{Resultados e Discussão}

A calagem teve influência expressiva sobre os atributos químicos do solo (Tabela 1), e apresentou interação significativa com os porta-enxertos na produção de raízes e frutos (Tabelas 2 e 3 e Figura 1). O preparo de solo, de forma isolada ou em interação com esses fatores, não exerceu influência relevante

Tabela 1. Atributos químicos do solo na área de projeção da copa de laranjeira 'Valência', em quatro profundidades do solo, em solos com e sem calagem, 14 anos após a implantação do experimento e dez anos após a última aplicação de calcário ${ }^{(1)}$.

\begin{tabular}{|c|c|c|c|c|c|c|c|c|}
\hline \multirow[t]{2}{*}{ Calagem } & \multirow{2}{*}{$\begin{array}{l}\text { Profundidade } \\
(\mathrm{cm})\end{array}$} & \multirow{2}{*}{$\begin{array}{c}\mathrm{pH} \\
\mathrm{CaCl}_{2} \\
\end{array}$} & $\mathrm{H}+\mathrm{Al}$ & Al & $\mathrm{Ca}$ & $\mathrm{Mg}$ & $\mathrm{V}$ & $\mathrm{m}^{(2)}$ \\
\hline & & & \multicolumn{4}{|c|}{ - } & \multicolumn{2}{|c|}{---------- $(\%)$--------- } \\
\hline Com & \multirow{2}{*}{$0-10$} & $4,76 \mathrm{a}$ & $3,63 b$ & $0,05 b$ & $1,89 \mathrm{a}$ & $0,84 \mathrm{a}$ & $43,9 \mathrm{a}$ & $2,2 b$ \\
\hline Sem & & $3,99 b$ & $5,31 \mathrm{a}$ & $0,67 \mathrm{a}$ & $0,82 b$ & $0,30 \mathrm{~b}$ & $18,6 b$ & $36,3 \mathrm{a}$ \\
\hline CV (\%) & & 8,9 & 14,3 & 43,8 & 40,6 & 16,3 & 28,7 & 44,7 \\
\hline Com & \multirow{2}{*}{$10-20$} & $4,67 \mathrm{a}$ & $3,41 b$ & $0,14 b$ & $1,50 \mathrm{a}$ & $0,72 \mathrm{a}$ & $40,2 \mathrm{a}$ & $6,6 b$ \\
\hline$\underline{\text { Sem }}$ & & $3,94 b$ & $5,34 \mathrm{a}$ & $0,94 \mathrm{a}$ & $0,50 \mathrm{~b}$ & $0,20 \mathrm{~b}$ & $12,8 b$ & $55,7 \mathrm{a}$ \\
\hline $\mathrm{CV}(\%)$ & & 7,2 & 11,8 & 27,7 & 38,6 & 35,1 & 24,9 & 30,8 \\
\hline Com & \multirow{2}{*}{$20-40$} & $4,53 \mathrm{a}$ & $3,37 b$ & $0,22 b$ & $1,04 \mathrm{a}$ & $0,85 \mathrm{a}$ & $36,4 a$ & $11,2 b$ \\
\hline$\underline{\text { Sem }}$ & & $3,97 \mathrm{~b}$ & $4,88 \mathrm{a}$ & $0,98 \mathrm{a}$ & $0,44 b$ & $0,22 b$ & $12,8 b$ & $58,9 \mathrm{a}$ \\
\hline $\mathrm{CV}(\%)$ & & 3,8 & 13,4 & 26,1 & 19,9 & 27,2 & 10,7 & 26,5 \\
\hline Com & \multirow{2}{*}{$40-60$} & $4,32 \mathrm{a}$ & $3,55 b$ & $0,42 b$ & $0,64 \mathrm{a}$ & $0,77 \mathrm{a}$ & $28,7 \mathrm{a}$ & $23,7 b$ \\
\hline Sem & & $4,02 b$ & $4,22 \mathrm{a}$ & $0,92 \mathrm{a}$ & $0,44 \mathrm{a}$ & $0,26 \mathrm{~b}$ & $14,3 \mathrm{~b}$ & $56,5 \mathrm{a}$ \\
\hline CV (\%) & & 6,8 & 9,1 & 22,0 & 48,4 & 49,6 & 23,4 & 25,8 \\
\hline
\end{tabular}

${ }^{(1)}$ Médias seguidas de letras iguais nas colunas, em cada profundidade de solo, não diferem entre si pelo teste de Tukey, a $5 \%$ de probabilidade. ${ }^{(2)}$ Saturação por alumínio. 
sobre as variáveis avaliadas, cujos resultados estão publicados em Auler (2010).

A calagem foi eficiente em promover alterações em todas as profundidades amostradas do solo, com aumento significativo dos valores de $\mathrm{pH}, \mathrm{Ca}, \mathrm{Mg}$, e saturação por bases, e redução de $\mathrm{H}+\mathrm{Al}, \mathrm{Al}$ trocável e saturação por $\mathrm{Al}$, com exceção dos teores de $\mathrm{Ca}$ à profundidade de 40-60 cm (Tabela 1). Essas alterações foram detectadas 14 anos após a aplicação inicial de calcário na implantação do experimento, e dez anos após a calagem superficial realizada no pomar. Apesar do longo tempo decorrido, as diferenças entre os tratamentos com e sem calagem foram consideráveis. Para $\mathrm{Ca}$, os ganhos foram de 130, 200 e 136\%, nas profundidades de $0-10,10-20$ e $20-40 \mathrm{~cm}$, respectivamente. Para $\mathrm{Mg}$, os ganhos foram de 180 , 260, 286 e 196\% e, para Al trocável, as reduções nos teores foram de $1.240,345,345$ e $119 \%$, para as

Tabela 2. Massa de matéria seca de raízes (MSR, g) de três porta-enxertos de laranjeira, a $0-60 \mathrm{~cm}$ de profundidade, em solo submetido ou não à calagem ${ }^{(1)}$.

\begin{tabular}{lcccc}
\hline Calagem & Cravo & Cleópatra & P. trifoliata & CV $(\%)$ \\
\hline Com & $0,595 \mathrm{Ab}$ & $1,166 \mathrm{Aa}$ & $0,962 \mathrm{Aab}$ & \multirow{2}{*}{25,4} \\
Sem & $0,594 \mathrm{Ab}$ & $1,152 \mathrm{Aa}$ & $0,426 \mathrm{Bb}$ & \\
\hline CV $(\%)$ & \multicolumn{5}{c}{32,3}
\end{tabular}

${ }^{(1)}$ Médias seguidas de letras iguais, maiúsculas nas colunas e minúsculas nas linhas, não diferem pelo teste Tukey, a 5\% de probabilidade.

Tabela 3. Produção acumulada de frutos e teores foliares de nutrientes, em laranjeira 'Valência' enxertada em diferentes porta-enxertos, com e sem calagem ${ }^{(1)}$.

\begin{tabular}{|c|c|c|c|c|}
\hline Variável & Calagem & Cravo & Cleópatra & P. trifoliata \\
\hline & & \multicolumn{3}{|c|}{ Produção acumulada (kg por planta) } \\
\hline \multirow{2}{*}{2006 a 2008} & Com & $373,8 \mathrm{Aab}$ & 403,0Aa & $333,5 \mathrm{Ab}$ \\
\hline & Sem & $348,4 \mathrm{Aa}$ & $346,7 \mathrm{Aa}$ & $238,8 \mathrm{Bb}$ \\
\hline CV (\%) & 15,7 & \multicolumn{3}{|c|}{12,2} \\
\hline \multirow{2}{*}{1996 a $2008^{(2)}$} & Com & $1.232,7 \mathrm{Aa}$ & $1.265,4 \mathrm{Aa}$ & $972,1 \mathrm{Ab}$ \\
\hline & Sem & $1.182,1 \mathrm{Aa}$ & $1.199,0 \mathrm{Aa}$ & $769,3 \mathrm{Bb}$ \\
\hline \multirow[t]{2}{*}{$\mathrm{CV}(\%)$} & 9,5 & \multicolumn{3}{|c|}{9,4} \\
\hline & & \multicolumn{3}{|c|}{ Teores foliares $\left(\mathrm{g} \mathrm{kg}^{-1}\right)$} \\
\hline \multirow{2}{*}{$\mathrm{Ca}$} & Com & $27,35 \mathrm{~A}$ & $33,93 \mathrm{~A}$ & $33,98 \mathrm{~A}$ \\
\hline & Sem & $26,55 \mathrm{~A}$ & $29,55 \mathrm{~A}$ & $27,05 \mathrm{~B}$ \\
\hline CV (\%) & 11,6 & \multicolumn{3}{|c|}{17,9} \\
\hline \multirow{2}{*}{$\mathrm{Mg}$} & Com & $3,78 \mathrm{~A}$ & $4,68 \mathrm{~A}$ & $5,95 \mathrm{~A}$ \\
\hline & Sem & $3,00 \mathrm{~A}$ & $3,56 \mathrm{~B}$ & $4,44 \mathrm{~B}$ \\
\hline CV (\%) & 16,3 & \multicolumn{3}{|c|}{18,1} \\
\hline
\end{tabular}

${ }^{(1)}$ Médias seguidas de letras iguais, maiúsculas nas colunas e minúsculas nas linhas, não diferem entre si pelo teste de Tukey, a 5\% de probabilidade. ${ }^{(2)}$ Exceto produção do ano de 1997. profundidades de 0-10, 10-20, 20-40 e 40-60 cm, respectivamente.

A calagem promoveu aumento no crescimento das raízes apenas em $P$. trifoliata, sem implicar diferenças significativas para os demais porta-enxertos. Em $P$. trifoliata, as médias de densidade de raízes sob calagem foram superiores às do tratamento sem calagem, nas profundidades de $10-20$ e $20-40 \mathrm{~cm}$ (Figura 1). Considerando-se a soma das quatro profundidades do solo, o incremento da MSR em P. trifoliata, no tratamento com calagem, foi de $126 \%$ (Tabela 2). A calagem também alterou o desempenho entre os porta-enxertos quanto à quantidade de raízes, pois, enquanto no tratamento sem calagem a MSR de

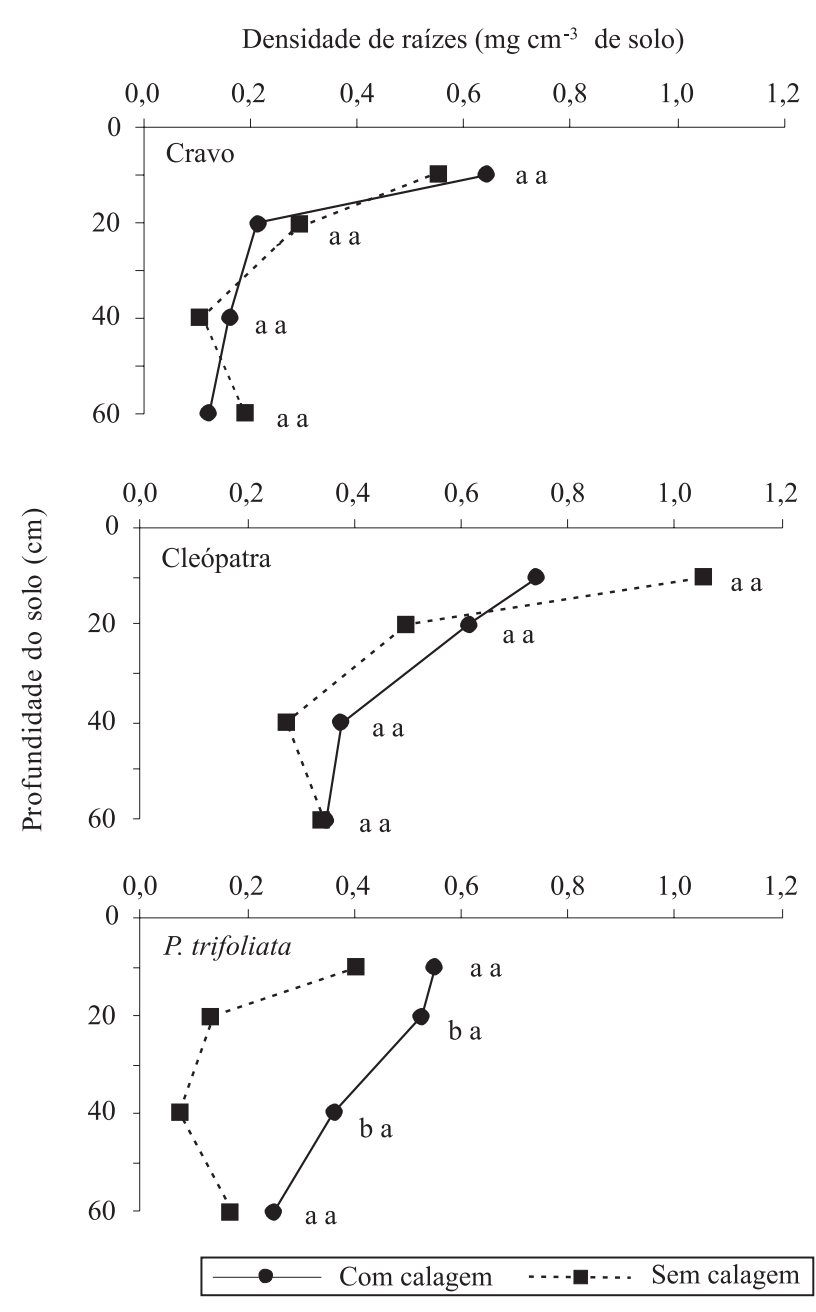

Figura 1. Densidade de raízes de laranjeira 'Valência' enxertada sobre os porta-enxertos 'Cravo', 'Cleópatra' e P. trifoliata, em quatro profundidades do solo. Em cada profundidade, médias seguidas por letras iguais não diferem entre si pelo teste de Tukey, a 5\% de probabilidade. 
'Cleópatra' foi superior à dos demais porta-enxertos, no tratamento com calagem ela não diferiu da MSR de P. trifoliata (Tabela 2).

Pavan \& Jacomino (1998) obtiveram incrementos significativos na MSR com a adição de calcário, em mudas de 'Cravo' e de 'Cleópatra', aos 10 meses após o transplante para vasos, em solo com $\mathrm{pH}$ em $\mathrm{CaCl}_{2}$ original de 4,4. Esses incrementos ocorreram a partir da correção do $\mathrm{pH}$ a 5,0 e 5,5, respectivamente para 'Cleópatra' e 'Cravo'; porém, apenas no tratamento com carbonato de cálcio. Quando a correção do $\mathrm{pH}$ foi feita com carbonato de magnésio, os autores não constataram incrementos na MSR. O teor inicial de Ca desse experimento, de $0,39 \mathrm{cmol}_{\mathrm{c}} \mathrm{dm}^{-3}$, foi menor do que o observado neste trabalho $\left(1,18 \mathrm{cmol}_{\mathrm{c}} \mathrm{dm}^{-3}\right)$; esse menor teor inicial de $\mathrm{Ca}$, possivelmente, está relacionado às diferenças de resposta à calagem entre esses experimentos.

A resposta em raízes, observada nos porta-enxertos, teve correspondência com a resposta para a produção de frutos (Tabela 3), em que a laranjeira 'Valência' foi beneficiada pela calagem de forma consistente apenas quando enxertada em $P$. trifoliata. Em 'Cravo' e 'Cleópatra' não houve diferenças na produção acumulada de frutos entre os tratamentos com e sem calagem. Em $P$. trifoliata, a calagem proporcionou aumento significativo da produção acumulada das 12 primeiras safras avaliadas (1996 a 2008), assim como das três últimas safras (2006 a 2008). Os ganhos em produção, em relação ao tratamento sem calagem para esses períodos, foram, respectivamente, de 26,4 e 39,6\%. Para 'Cravo' e 'Cleópatra', a produtividade de frutos nessas três últimas safras, no tratamento sem calagem, foi de aproximadamente $41 \mathrm{Mg} \mathrm{ha}^{-1}$ por ano, o que mostra, a ausência de dependência da calagem pela laranjeira 'Valência' sobre estes porta-enxertos, para manter boa produtividade até os 14 anos após o plantio.

Na comparação da produção acumulada de 1996 a 2008, entre porta-enxertos na presença e na ausência da calagem, 'Cravo' e 'Cleópatra' tiveram produções equivalentes entre si e superiores à de $P$. trifoliata, resultado que se atribui ao menor porte induzido por este porta-enxerto às copas das plantas (Stenzel et al., 2005; Auler, 2010). Na produção acumulada de 2006 a 2008, houve influência da calagem, em que a produção em $P$. trifoliata se equiparou à de 'Cravo' no tratamento com calagem (Tabela 3), desempenho que está de acordo com o resultado de MSR desses porta-enxertos (Tabela 2).

No Brasil, nos trabalhos realizados com laranjeiras para avaliar a resposta à calagem em termos de produção, utilizou-se, em sua maioria, apenas o porta-enxerto 'Cravo', cujos resultados variaram entre ausência de resposta a resposta com incrementos de baixa magnitude, em copas de laranjeira 'Valência' (Quaggio et al., 1998) e 'Natal' (Calgaro et al., 2007). Esses resultados estão de acordo com os obtidos no presente trabalho, em que o uso da calagem não proporcionou diferenças significativas $(4,3 \%)$ sobre a produção acumulada de frutos das 12 primeiras safras de ' Valência' sobre ' Cravo' (Tabela 3).

Em revisão sobre o assunto, Boaretto et al. (1996) analisaram seis trabalhos realizados no Brasil sobre calagem em citros, cinco deles com 'Cravo', e destacaram que foi obtida pequena resposta à calagem - 1 a $13 \%$ de aumento na produtividade -, quando o solo, na camada de 0-20 cm, já tinha inicialmente saturação por bases entre 33 e $45 \%$, faixa em que também se encaixa o valor inicial de $34,8 \%$ observado no presente estudo.

Em P. trifoliata, Panzenhagen et al. (1999) não encontraram efeitos significativos da calagem na produção das três primeiras safras de tangerineira 'Montenegrina', em solo com pH inicial de 5,5. Em Cleópatra, Silva et al. (2007) não observaram diferenças na produção de frutos de laranjeira 'Pêra', com 14 anos de idade, após a aplicação de calcário calcinado em superfície, em solo com saturação por bases inicial de $57 \%$. Essa baixa resposta à calagem, obtida nesses trabalhos e no presente estudo, talvez possa ser atribuída ao fato de as plantas cítricas serem mais adaptadas a valores de $\mathrm{pH}$ abaixo de 5,4 $\left(\mathrm{CaCl}_{2} 0,01 \mathrm{~mol} \mathrm{~L}^{-1}\right)$, já que são plantas originadas dos trópicos úmidos, com solos naturalmente ácidos (Wutscher, 1989).

Resultados expressivos de resposta à calagem em citros foram obtidos por Anderson (1987), na Flórida, em laranjeira 'Valência' sobre limoeiro 'Rugoso', em que, em 11 safras, ocorreu um acréscimo de 76,2\% na produção de frutos no tratamento com calcário. Porém, o experimento desses autores reuniu condições com CTC de $2 \mathrm{cmol}_{\mathrm{c}} \mathrm{dm}^{-3} \mathrm{e}$ teores iniciais de $\mathrm{Ca}$, na camada de $0-15 \mathrm{~cm}$, de aproximadamente $0,14 \mathrm{cmol}_{\mathrm{c}} \mathrm{dm}^{-3}$, valores bem inferiores aos dos teores originais de $\mathrm{Ca}$ do presente estudo. 
A calagem produziu aumento significativo dos teores foliares de $\mathrm{Ca}$ e $\mathrm{Mg}$, nas laranjeiras sobre $P$. trifoliata (Tabela 3). Em 'Cleópatra', os teores de Ca não foram afetados e os de Mg aumentaram na presença de calagem. Em 'Cravo', a nutrição de Ca e Mg não foi alterada de forma significativa pelo uso da calagem, apesar de esta ter proporcionado maior disponibilidade desses nutrientes no perfil do solo. Para os três porta-enxertos, os teores de Ca ficaram abaixo do teor foliar mínimo de $35 \mathrm{~g} \mathrm{~kg}^{-1}$, considerado adequado para citros, enquanto os teores de $\mathrm{Mg}$ atingiram, tanto no tratamento com calagem como no sem calagem, o mínimo de $3 \mathrm{~g} \mathrm{~kg}^{-1}$ estabelecido como adequado por Mattos Júnior et al. (2009). Nos porta-enxertos 'Cleópatra' e 'Cravo', não houve contradição entre os níveis nutricionais obtidos e as faixas de interpretação propostas por estes autores; entretanto, o padrão observado de nutrição foliar de $\mathrm{Mg}$ da laranjeira 'Valência' sobre P. trifoliata (Tabela 3) não se ajustou à referida faixa, pois teores foliares deste nutriente, acima de 5,0 $\mathrm{g} \mathrm{kg}^{-1}$, considerados excessivos acima deste teor, resultaram em melhor crescimento de raízes (Tabela 2 e Figura 1) e produção de frutos (Tabela 3).

Em pomares cultivados em solos da mesma formação da do presente estudo, foram detectados teores foliares médios de 33,1 $\mathrm{g} \mathrm{kg}^{-1}$ de $\mathrm{Ca}$ e de 2,6 $\mathrm{g} \mathrm{kg}^{-1}$ de $\mathrm{Mg}$, em pomares considerados de alta produtividade de laranjeira 'Valência' sobre 'Cravo' (Fidalski et al., 2000). Nesse mesmo solo, também foram constatados teores foliares mais elevados de $\mathrm{Mg}$ em folhas de laranjeira 'Folha Murcha' enxertada sobre $P$. trifoliata, em relação às enxertadas sobre 'Cravo' (Fidalski \& Stenzel, 2006).

Os maiores valores de $\mathrm{pH}, \mathrm{Ca}$ e $\mathrm{Mg}$ e os menores de $\mathrm{Al}$ trocável e de $\mathrm{H}+\mathrm{Al}$ no solo, proporcionados pela calagem (Tabela 1), beneficiaram o desenvolvimento do sistema radicular da laranjeira 'Valência' enxertada em P. trifoliata (Tabela 2 e Figura 1), o que trouxe reflexos positivos sobre a nutrição das plantas e a produção de frutos (Tabela 3). A relação de dependência entre essas variáveis do solo e da planta é reforçada pelas correlações significativas obtidas entre elas (Tabela 4). Às profundidades de 10-20 e 20-40 cm do solo, ocorreram correlações negativas entre a MSR de $P$. trifoliata e os teores de Al, e foram observadas correlações positivas entre a MSR e o $\mathrm{pH}$ e os teores de $\mathrm{Ca}$ e $\mathrm{Mg}$.

No entanto, em 'Cravo' não foi observada qualquer correlação significativa entre a MSR e pH e teores de $\mathrm{Ca}, \mathrm{Mg}$ e Al trocável do solo. Em 'Cleópatra', apenas observou-se uma correlação positiva entre a MSR e os teores de $\mathrm{Mg}$, à profundidade de 10-20 cm, e outra entre MSR e o $\mathrm{pH}$ a $40-60 \mathrm{~cm}$. Esses resultados indicam menor sensibilidade de 'Cravo' e 'Cleópatra' à acidez do solo e ao Al trocável, e menor exigência em Ca e $\mathrm{Mg}$, em comparação a $P$. trifoliata, embora 'Cleópatra' tenha demonstrado certa sensibilidade à acidez e maior exigência por $\mathrm{Mg}$. Possivelmente, os teores de $\mathrm{Ca}$ e $\mathrm{Mg}$ e o $\mathrm{pH}$ do solo não foram suficientemente baixos, nem os teores de Al suficientemente altos, para comprometer o crescimento das raízes e a produção de frutos da laranjeira 'Valência' sobre 'Cravo' e 'Cleópatra', porta-enxertos cuja sensibilidade de raízes já foi demonstrada a partir da exposição a maiores concentrações de Al trocável (Nogueira et al., 1989; Pereira et al., 2003) e menores de Ca (Anderson, 1987; Pavan \& Jacomino, 1998; Grassi Filho et al., 2004).

Compostos orgânicos liberados no solo podem complexar-se ao Al (Meda et al., 2002; Pavan \& Miyazawa, 2004). Dessa forma, a cobertura vegetal permanente nas entrelinhas das laranjeiras e a de plantas invasoras na faixa de plantio podem ter contribuído para atenuar a toxicidade do $\mathrm{Al}$, o que explicaria porque os níveis de saturação elevados observados no tratamento sem calagem (Tabela 1) não inibiram o crescimento radicular de 'Cravo' e 'Cleópatra' e não afetaram a produção das laranjeiras.

Para $P$. trifoliata, foi possível ajustar os dados de densidade de raízes em função dos teores de $\mathrm{Ca}$,

Tabela 4. Coeficientes de correlações de Pearson (r) entre as variáveis massa de matéria seca de raízes de laranjeira 'Valência' em três porta-enxertos, em quatro profundidades, e os atributos químicos do solo das mesmas profundidades.

\begin{tabular}{|c|c|c|c|c|c|c|c|c|c|c|c|c|}
\hline \multirow[t]{2}{*}{ Atributo } & \multicolumn{4}{|c|}{ Cravo } & \multicolumn{4}{|c|}{ Cleópatra } & \multicolumn{4}{|c|}{ P. trifoliata } \\
\hline & $0-10$ & $10-20$ & $20-40$ & $40-60$ & $0-10$ & $10-20$ & $20-40$ & $40-60$ & $0-10$ & $10-20$ & $20-40$ & $40-60$ \\
\hline $\mathrm{pH}$ & ns & ns & ns & ns & ns & ns & ns & $0,57 *$ & ns & $0,61 *$ & ns & ns \\
\hline $\mathrm{Al}$ & ns & ns & ns & ns & ns & ns & $\mathrm{ns}$ & ns & ns & $-0,82 * *$ & $-0,72 * *$ & ns \\
\hline $\mathrm{Ca}$ & ns & ns & $\mathrm{ns}$ & ns & ns & ns & $\mathrm{ns}$ & ns & ns & $0,67^{*}$ & $0,59 *$ & ns \\
\hline $\mathrm{Mg}$ & ns & ns & $\mathrm{ns}$ & ns & ns & $0,70^{*}$ & ns & ns & ns & $0,67^{*}$ & $0,73^{* *}$ & ns \\
\hline
\end{tabular}

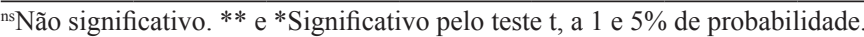


$\mathrm{Mg}$ e $\mathrm{Al}$ no solo. As curvas de regressão quadráticas para $\mathrm{Ca}\left(\mathrm{R}^{2}=0,87\right)$ e de $\mathrm{Mg}\left(\mathrm{R}^{2}=0,81\right)$ indicam que a resposta em crescimento das raízes de $P$. trifoliata, nesse solo, atinge um ponto máximo com teores de 1,2 e de $0,82 \mathrm{cmol}_{\mathrm{c}} \mathrm{dm}^{-3}$, respectivamente (Figura 2). $\mathrm{O}$ valor para $\mathrm{Mg}$ é equivalente ao valor de $0,8 \mathrm{cmol}_{\mathrm{c}} \mathrm{dm}^{-3}$ recomendado para o cultivo de citros (Quaggio et al., 2005). O intercepto dessas curvas indica a ausência de crescimento de raízes em teores estimados de $0,28 \mathrm{cmol}_{\mathrm{c}} \mathrm{dm}^{-3}$, para Ca, e de $0,1 \mathrm{cmol}_{\mathrm{c}} \mathrm{dm}^{-3}$ para $\mathrm{Mg}$, o que evidencia a essencialidade desses nutrientes para o crescimento de raízes, especialmente em relação ao Ca, como observado por Pavan \& Jacomino (1998). A resposta quadrática da MSR de $P$. trifoliata aos teores de Ca está em acordo com relatos de Stacey (1973),
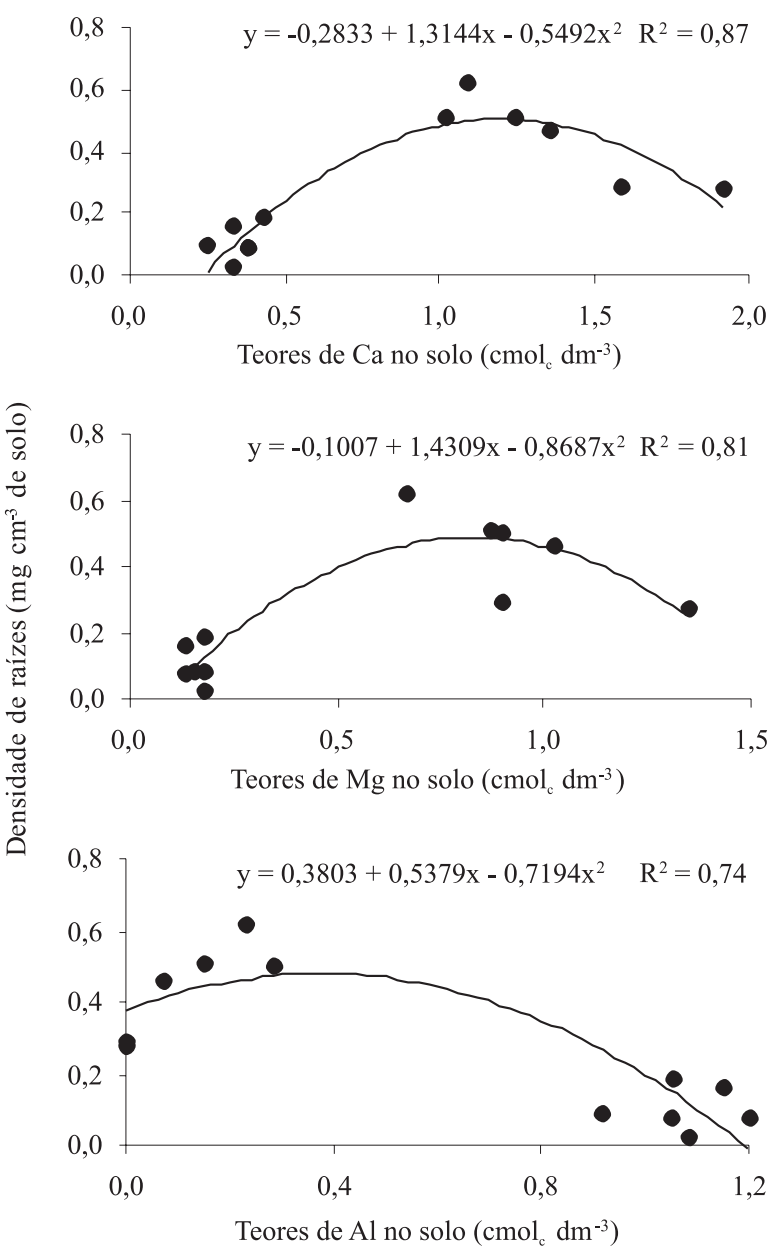

Figura 2. Densidade de raízes de laranjeira 'Valência' enxertada no porta-enxerto $P$. trifoliata, em função dos teores de $\mathrm{Ca}, \mathrm{Mg}$ e $\mathrm{Al}$ trocável no solo, nas camadas de 10-20 e 20-40 cm de profundidade. que verificou efeitos adversos provocados por níveis elevados de $\mathrm{Ca}$ e pH (acima de 5,7) no solo, como menor desenvolvimento e clorose de folhas das plantas enxertadas nesse porta-enxerto.

No caso do Al, o gráfico da equação de regressão $\left(\mathrm{R}^{2}=0,74\right)$ indica intensa redução na densidade de raízes do $P$. trifoliata a partir de teores de $0,37 \mathrm{cmol}_{\mathrm{c}} \mathrm{dm}^{-3}$ no solo (Figura 2). Santos et al. (1999) também verificaram que, enquanto a massa de folhas secas, caules e raízes de mudas de limoeiro 'Cravo', em solução nutritiva, não foram influenciadas até a concentração de $30 \mathrm{mg} \mathrm{L}^{-1}$ de $\mathrm{Al}$, as de citrumeleiro 'Swingle', um híbrido de $P$. trifoliata, mostraram sensibilidade a partir da concentração de $7,5 \mathrm{mg} \mathrm{L}^{-1}$, com redução significativa na MSR a partir da concentração de $15 \mathrm{mg} \mathrm{L}^{-1}$.

O conjunto dos resultados apresentados mostrou uma importante diferença no padrão de adaptação aos atributos químicos do solo, alterados pela calagem, pela laranjeira 'Valência' enxertada em $P$. trifoliata, em comparação à mesma copa enxertada em 'Cravo' e 'Cleópatra'. A observação dessas diferenças e das condições do solo em que elas se deram poderão contribuir para o aprimoramento do manejo nutricional dos pomares de laranja, com maior racionalização no uso do insumo calcário e, ao mesmo tempo, maior produtividade das plantas pelo atendimento das exigências nutricionais específicas de cada porta-enxerto.

\section{Conclusões}

1. O porta-enxerto Poncirus trifoliata é mais sensível à acidez e ao $\mathrm{Al}$ trocável e a menores teores de $\mathrm{Ca}$ e $\mathrm{Mg}$ do solo, em comparação ao 'Cravo' e ao 'Cleópatra'.

2. No porta-enxerto 'Cleópatra', o uso de calcário aumenta os teores foliares de $\mathrm{Mg}$ da laranjeira 'Valência', mas não aumenta a massa de matéria seca de raízes e a produção de frutos.

3. O porta-enxerto 'Cravo' apresenta elevada tolerância à acidez do solo e não responde ao uso de calcário dentro dos limites de acidez e de teores de $\mathrm{Ca}$, $\mathrm{Mg}$ e Al observados neste trabalho.

\section{Agradecimentos}

Ao Grupo Pratinha, pelo apoio na condução do experimento; ao Sr. Paulo Manoel de Lima, pelo auxílio nas avaliações; e à Fundação Araucária, pelos recursos financeiros. 


\section{Referências}

ANDERSON, C.A. Fruit yields, tree size, and mineral nutrition relationships in 'Valencia' orange trees as affected by liming. Journal of Plant Nutrition, v.10, p.1907-1916, 1987.

AULER, P.A.M. Preparo do solo, calagem e porta-enxertos para o cultivo de laranjeira 'Valência'. 2010. 138p. Tese (Doutorado) - Universidade Estadual de Londrina, Londrina.

AULER, P.A.M.; FIDALSKI, J.; PAVAN, M.A.; NEVES, C.S.V.J. Produção de laranja 'Pêra' em sistemas de preparo do solo e manejo nas entrelinhas. Revista Brasileira de Ciência do Solo, v.32, p.363-374, 2008.

BOARETTO, A.E.; MURAOKA, T.; RÊGO, I.C. Calagem e gessagem em citricultura. In: SEMINÁRIO INTERNACIONAL DE CITROS: NUTRIÇÃO E ADUBAÇÃO, 4., 1996, Bebedouro. Anais. Campinas: Fundação Cargil, 1996. p.115-129.

CALGARO, H.F.; FERNANDES, F.M.; BOAVENTURA, A.L. de A.; TARSITANO, M.A.A. Modos de aplicação de calcário e de micronutrientes em pomar de laranjeira 'Natal' e análise comparativa de custos. Revista Brasileira de Fruticultura, v.29, p.639-644, 2007.

FIDALSKI, J.; AULER, P.A.M.; TORMEN, V. Relations among 'Valencia' orange yields with soil and leaf nutrients in northwestern Paraná, Brazil. Brazilian Arquives of Biology and Technology, v.43, p.387-391, 2000.

FIDALSKI, J.; STENZEL, N.M.C. Nutrição e produção da laranjeira 'Folha Murcha' em porta-enxertos e plantas de cobertura permanente na entrelinha. Ciência Rural, v.36, p.807-813, 2006.

GRASSI FILHO, H.; DECHEN, A.R.; TORQUATO, E.M.; SANTOS, C.H. dos. Fenologics characteristics of the 'Siciliano' lemon tree on two rootstocks influenced by liming and boron addition. Brazilian Archives of Biology and Technology, v.47, p.677-684, 2004.

MATTOS JÚNIOR, D.; BATAGLIA, O.C.; QUAGGIO, J.A. Nutrição dos citros. In: MATTOS JÚNIOR, D. de; DE NEGRI, J.D.; PIO, R.M.; POMPEU JUNIOR, J. (Ed.). Citros. Campinas: Instituto Agronômico: Fundag, 2005. p.198-219.

MATTOS JÚNIOR, D.; QUAGGIO, J.A.; CANTARELLA, H.; BOARETTO, R.M. Citrus: manejo da fertilidade do solo para alta produtividade. Informações Agronômicas, n.128, p.5-12, 2009.

MEDA, A.R.; PAVAN, M.A.; MIYAZAWA, M.; CASSIOLATO, M.E. Plantas invasoras para melhorar a eficiência da calagem na correção da acidez subsuperficial do solo. Revista Brasileira de Ciência do Solo, v.26, p.647-654, 2002.

MIYAZAWA, M.; PAVAN, M.A.; BLOCH, M. de F.M. Análise química de tecido vegetal. Londrina: Iapar, 1992. 17p. (Iapar. Circular, 74).

NOGUEIRA, S. dos S.S.; NAGAI, V.; CARELLI, M.L.C.; FAHL, J.I. Comportamento de porta-enxertos de citros em presença do alumínio. Pesquisa Agropecuária Brasileira, v.24, p.711-716, 1989.
PANZENHAGEN, N.V.; KOLLER, O.C.; SARTORI, I.A.; PORTELINHA, N.V. Respostas de tangerineiras 'Montenegrina' à calagem e adubação orgânica e mineral. Pesquisa Agropecuária Brasileira, v.34, p.527-533, 1999.

PAVAN, M.A.; JACOMINO, A.P. Root growth and nutrient contents of citrus rootstocks in an acid soil with varied $\mathrm{pH}$. Ciência e Cultura, v.50, p.56-59, 1998.

PAVAN, M.A.; MIYAZAWA, M. Plantas de cobertura: uma alternativa para melhorar a eficiência da calagem em solos ácidos. Citricultura Atual, n.38, p.12-13, 2004.

PEREIRA, W.E.; SIQUEIRA, D.L. de; PUIATTI, M.; MARTÍNEZ, C.A.; SALOMÃO, L.C.C.; CECON, P.R. Growth of citrus rootstocks under aluminium stress in hydroponics. Scientia Agricola, v.60, p.31-41, 2003.

QUAGGIO, J.A.; MATTOS JÚNIOR, D.; CANTARELLA, H. Manejo da fertilidade do solo na citricultura. In: MATTOS JÚNIOR, D. de; DE NEGRI, J.D.; PIO, R.M.; POMPEU JUNIOR, J. (Ed.). Citros. Campinas: Instituto Agronômico: Fundag, 2005. p.483-507.

QUAGGIO, J.A.; ROSA, S.M.; MATTOS JUNIOR, D.; RAIJ, B. van. Resposta da laranjeira 'Valência' à aplicação de calcário de gesso. Laranja, v.19, p.383-398, 1998.

QUAGGIO, J.A.; TEÓFILO SOBRINHO, J.; DECHEN. Response to liming of 'Valência' orange tree on rangpur lime: effects of soil acidity on plant growht and yield. Proceedings of the International Society of Citriculture, v.2, p.628-632, 1992.

SANTOS, C.H. dos; GRASSI FILHO, H.; RODRIGUES, J.D.; PINHO, S.Z. de. Níveis de alumínio e acúmulo de macronutrientes em porta-enxertos cítricos em cultivo hidropônico. Scientia Agricola, v.56, p.1165-1175, 1999.

SILVA, M.A.C. da; NATALE, W.; PRADO, R. de M.; CORRÊA, M.C.M.; STUCHI, E.S.; ANDRIOLI, I. Aplicação superficial de calcário em pomar de laranjeira 'Pêra' em produção. Revista Brasileira de Fruticultura, v.29, p.606-612, 2007.

SOBRAL, L.F.; CINTRA, F.L.D.; SMYTH, J.T. Lime and gypsum to improve root depth of orange crop in an Ultisol of the Coastal Tablelands. Revista Brasileira de Engenharia Agrícola e Ambiental, v.13, p.836-839, 2009.

SOUZA, L.D.; SOUZA, L. da S.; LEDO, C.A. de S. Sistema radicular dos citros em Neossolo Quartzarênico dos Tabuleiros Costeiros sob irrigação e sequeiro. Pesquisa Agropecuária Brasileira, v.42, p.1373-1381, 2007.

STACEY, W. Over-liming of citrus. New Zealand Journal of Agriculture, v.126, p.40-41, 1973.

STENZEL, N.M.C.; NEVES, C.S.V.J.; SCHOLZ, M.B. dos S.; GOMES, J.C. Comportamento da laranjeira 'Folha Murcha' em sete porta-enxertos no noroeste do Paraná. Revista Brasileira de Fruticultura, v.27, p.408-411, 2005.

WUTSCHER, H.K. Soil pH and extractable elements under blight-affected and healthy citrus trees on six Florida soils. Journal of the American Society for Horticultural Science, v.114, p.611-614, 1989.

Recebido em 11 de julho de 2010 e aprovado em 8 de fevereiro de 2011 